\title{
UV Spectrophotometric Determination of Thermodynamic Dissociation Constants of Some Aromatic Hydrazones in Acid Media
}

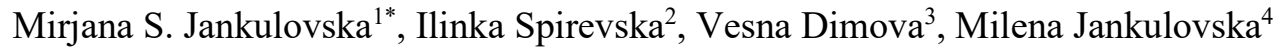 \\ ${ }^{1}$ Cyril and Methodius University, Faculty of Agricultural Sciences and Food in Skopje, Macedonia. e-mail: \\ msjankulovska@gmail.com (Milena Jankulovska). \\ ${ }^{2}$ Cyril and Methodius University, Faculty of Natural Sciences and Mathematics in Skopje, Macedonia. e-mail: \\ spirevska@yahoo.com (Ilinka Spirevska). \\ ${ }^{3}$ Cyril and Methodius University, Faculty of Technology and Metallurgy in Skopje, Macedonia. e-mail: \\ vdimova@tmf.ukim.edu (Vesna Dimova). \\ ${ }^{4}$ University Ss. Kliment Ohridski, Chemical-Bromatological-Toxicological Analysis Laboratory, Higher \\ Medical School in Bitola, Macedonia.
}

*Corresponding author: Mirjana S. Jankulovska e-mail: jankulovska_m@yahoo.com

Received March $3^{\text {rd }}, 2019 ;$ Accepted July $15^{\text {th }}, 2019$.

DOI: http://dx.doi.org/10.29356/jmcs.v63i4.794

\begin{abstract}
The spectral behavior of some $p$-nitro- $p$-substituted benzoylhydrazones in the perchloric acid media was followed, applying the UV spectroscopy. The position of the absorption maximum in the spectra was defined in acidic media and the electronic transitions were discussed, as well $(1<\mathrm{pH}<7)$. The equilibrium between neutral and protonated form was investigated in the ethanol-water $(V / V, 1: 1)$ solutions. The observed changes in the UV spectra suggested that protonation process took place in one step. The $\mathrm{pH}$ region of protonation ranges between 1.4 and 2.9. Using the changes in the UV spectra which appear as a result of the protonation reaction the stoichiometric dissociation constants were determined numerically $\left(\mathrm{p} K_{\mathrm{BH}}{ }^{+}=n \cdot \mathrm{pH}+\right.$ $\log I$ ) and graphically (intercept of the dependence of $\log I$ on $\mathrm{pH}$ ). Thermodynamic dissociation constants were estimated as an intercept of dependence of $\mathrm{p}_{\mathrm{BH}^{+}}{ }^{+}$on square root of the ionic strength. In order to achieve that, measurements were performed at different ionic strengths: $0.1,0.25$ and $0.5 \mathrm{~mol} / \mathrm{dm}^{3}$, adjusted with sodium perchlorate. The obtained thermodynamic $\mathrm{p} \mathrm{BH}^{+}$values ranged between 2.07 and 2.58. In order to predict proton transfer at a given $\mathrm{pH}$, semiempirical methods AM1 and PM3 were applied. The influence of the substituents present in the $p$-position of the benzene ring on $\mathrm{pK}_{\mathrm{BH}}{ }^{+}$values of investigated hydrazones was discussed, too. Total energy, binding energy, enthalpy of formation, Gibbs energies of formation, atomic charge and proton affinity values were used to predict protonation site in hydrazone molecule. Furthermore, the stability and the proton affinity of the isomers $(E$ and $Z)$ in which hydrazones exist and their protonated forms were defined.

Keywords: $p$-nitro- $p$-substituted benzoylhydrazones; dissociation constants; protonation; UV spectroscopy; semiempirical AM1 and PM3 methods.

Resumen. Se siguió el comportamiento espectral de algunas benzoilhidrazonas p-nitro-p sustituidas utilizando ácido perclórico como medio y aplicando espectroscopía UV. La absorción máxima en los espectros se definió en medios ácidos y también se discutieron las transiciones electrónicas $(1<\mathrm{pH}<7)$. Se investigó el equilibrio entre la forma neutra y protonada en soluciones de etanol-agua $(\mathrm{V} / \mathrm{V}, 1: 1)$. Los cambios observados en los espectros UV sugirieron que el proceso de protonación tuvo lugar en un sólo paso. La región de protonación oscila en el intervalo de $\mathrm{pH}$ entre 1.4 y 2.9. Utilizando los cambios en el espectro de UV que surgen como resultado de la reacción de protonación, las constantes de disociación estequiométricas fueron determinadas numérica $\left(\mathrm{pK}_{\mathrm{BH}}{ }^{+}=\mathrm{n} \cdot \mathrm{pH}+\log \mathrm{I}\right)$ y gráficamente (intercepción de la dependencia de logI en el $\mathrm{pH}$ ). Las
\end{abstract}


constantes de disociación termodinámicas fueron estimadas como una intersección en la dependencia de $\mathrm{p} K_{\mathrm{BH}}^{+}$ con la raíz cuadrada de la fuerza iónica. Para conseguir lo anterior, se realizaron mediciones a diferentes fuerzas iónicas: $0.1,0.25$ y $0.5 \mathrm{~mol} / \mathrm{dm}^{3}$, ajustadas con perclorato de sodio. Los valores termodinámicos de $\mathrm{pK}_{\mathrm{BH}}{ }^{+}$ obtenidos oscilaron entre 2.07 y 2.58. Para predecir la transferencia de protones a un $\mathrm{pH}$ dado, se utilizaron los métodos semiempíricos AM1 y PM3. También, se discutió la influencia de los sustituyentes presentes en la posición $p$ del anillo de benceno de los valores $\mathrm{pK}_{\mathrm{BH}^{+}}{ }^{+}$de las hidrazonas investigadas. Para predecir el sitio de protonación en la molécula de hidrazona, se utilizaron los valores de energía total, energía de unión, entalpía de formación, energía de Gibbs, carga atómica y afinidad protónica. Además, se definió la estabilidad y la afinidad protónica de isómeros $(E \mathrm{y} Z)$ en las cuales existen las hidrazonas y sus formas protonadas.

Palabras clave: Benzoilhidrazonas p-nitro-p sustituidas; constantes de disociación; protonación; espectroscopía UV; métodos semi empíricos AM1 y PM3.

\section{Introduction}

Aroylhydrazones and their derivatives constitute a versatile class of compounds in organic chemistry. They are a class of azomethines having the structure: $\mathrm{Ar}-\mathrm{CO}-\mathrm{NH}-\mathrm{N}=\mathrm{CR}_{1} \mathrm{R}_{2}$. Aroylhydrazones contain two interlinked nitrogen atoms of different nature and nucleophilic character, and a carbon atom which may act as either electrophile or nucleophile, according to the reaction environment $[1,2]$. In their structure is also presented a $\mathrm{C}=\mathrm{N}$ double bond that is conjugated with a lone electron pair of the terminal nitrogen atom. These structural fragments are mainly responsible for the physical and the chemical properties of hydrazones. Both nitrogen atoms of the hydrazone group are nucleophilic, although the amino type nitrogen is more reactive. The carbon atom of hydrazone group has both electrophilic and nucleophilic character. Due to their structure hydrazones are important compounds for drug design and, as possible ligands for metal complexes, organocatalysis and for the syntheses of heterocyclic compounds [3]. There is a growing interest in the structural studies of Aroylhydrazones, as they show a broad spectrum of applications in pharmaceutical and industrial fields [4]. These observations increased the need for the development of new hydrazones that possess varied biological activities [5-7]. Literature studies revealed that hydrazones, and various substituted hydrazones are associated with a broad spectrum of biological activities such as: antioxidant, antibacterial, antiviral, analgesic, antiplatelet, antimicrobial, and anticancer activities etc [8,9].

In order to combat diseases with minimal toxicity and maximal effects, hydrazones are synthesized as drugs by many researchers. These predictions have provided therapeutic pathway for developing a new effective biologically active hydrazones [10]. Hydrazones are very effective organic compounds, but at the same time they are used as intermediates to prepare some biological active compounds by using the active hydrogen atom of $\mathrm{CONHN}=\mathrm{CH}-$ azomethine group $[6,8]$.

Hydrazones also have analytical applications, which attract so many researchers [11]. They are very important group of analytical regents for determination of various metal ions, by using different analytical techniques [12]. Hydrazone derivatives may act as multidentate ligands and their transition metals complexes were already used in the treatment of tuberculosis, in colorimetric or fluorimetric determinations, as well as, in applications involving catalytic processes $[13,14]$. Hydrazones are also important intermediates in the syntheses of nitrogen containing heterocyclic compounds [3]. Furthermore, hydrazones possess pesticide effects (herbicides, insecticides, nematocides, rodenticides) and plant growth regulators activity [15]. Many hydrazone derivatives have been reported to possess broad spectrum of insecticidal activities, and they can be used as active ingredients for controlling agricultural and horticultural pests [16,17].

The biological activity of hydrazones and their derivatives depends on the ionic form which exists in the solution. Hydrazones have acidic and basic functional groups and their ionization state is controlled by both, $\mathrm{pH}$ of the solution, and the value of dissociation constants. Dissociation constant is the most valuable parameter to understand chemical phenomenon such as: biological activity, absorption and extent of ionization of compound in different $\mathrm{pH}$. So, it is the key parameter in drug development and optimization of the dose [18]. Dissociation constants are also of vital importance in understanding and optimization of analytical procedures 
like acid-base titration, solvent extraction and complex formation. The accurate determination of dissociation constant values is often required in many chemical and biochemical areas.

There are various techniques available for determination of dissociation constant such as: potentiometric titration, nuclear magnetic resonance (NMR), capillary electrophoresis (CE), chromatography (HPLC), hyper-Rayleigh scattering technique, UV spectroscopic methods etc. The ultraviolet-visible spectrophotometry is one of the most frequently employed techniques for determination of dissociation constant [18]. Knowing the $\mathrm{pK}_{\mathrm{BH}}{ }^{+}$values of a drug, and the $\mathrm{pH}$ of the absorption site, the relative amount of ionized and unionized drug in a solution at a particular $\mathrm{pH}$, and the percent of drug ionized at this $\mathrm{pH}$, can be determined $[19,20]$. Because of that, there is a considerable interest in using experimental methods for determination of the $\mathrm{p} K_{\mathrm{BH}}{ }^{+}$values of different types of organic compounds.

The aim of the present work was to investigate the acid-base behavior of some $p$-nitro-p-substituted benzoylhydrazones, in perchloric acid media $(7<\mathrm{pH}<1)$, as well as, to determine the stoichiometric dissociation constant of protonated form at different ionic strength, and thermodynamic dissociation constant values at constant ionic strength. In order to eliminate the influence of the solvent on the protonation reaction, method of characteristic vector analysis (CVA) was employed [21,22]. Protonation site of hydrazone molecule, stability of protonated form of $E$ and $Z$ isomers and influence of the substituent were determined using semiempirical data obtained applying semiempirical methods AM1 and PM3 [23,24].

\section{Experimental}

\section{Chemicals and instrumentation}

The investigated benzoylhydrazones were purified by recrystallization from ethanol or diluted ethanol (ethanol/water $=1 / 1, V / V$ ). The purity was tested by measuring the melting point, as well as, by elemental analysis. The perchloric acid, sodium perchlorate and ethanol were of analytical grade p.a. (Merck), and they were used without further purification. A digital $\mathrm{pH}$ meter with glass electrode was used for measurements of the $\mathrm{pH}$ values ( $\mathrm{pH}$ range from 1 to 14). The spectral measurements were carried out on a Varian Cary 50 spectrophotometer controlled by a computer and equipped with a $1 \mathrm{~cm}$ path length quartz cell, in the wavelength region from 190 to $400 \mathrm{~nm}$. The maximum scan rate was $24000 \mathrm{~nm} / \mathrm{min}$ with the resolution of $1.5 \mathrm{~nm}$. An Excel program was applied for calculation of the dissociation constants, while the UV spectra were obtained with computer program Grams Version 4.10.

\section{Stock and test solutions}

The stock solutions of investigated hydrazones were prepared by dissolving an accurate weight of the compound in the appropriate volume of $98 \%$ ethanol, in a volumetric flask of $250 \mathrm{~cm}^{3}$. The concentration of the investigated hydrazones in these solutions was about $1 \cdot 10^{-3} \mathrm{~mol} / \mathrm{dm}^{3}$. The stock solutions were stable over a long period of time, under ordinary conditions, which was confirmed with the recorded UV spectra. The test solution was prepared from the stock solution with appropriate dilution in order to achieve concentration of investigated hydrazones in the test solution of about $3 \cdot 10^{-5} \mathrm{~mol} / \mathrm{dm}^{3}$. Because of the low solubility of investigated hydrazones in aqueous solutions the test solutions were prepared in redistilled water and ethanol with volume ratio 1:1 $(V / V)$. The stability of these solutions was satisfactory for only 24 hours of time. A constant amount of sodium perchlorate $\left(1 \mathrm{~mol} / \mathrm{dm}^{3}\right)$ was added in the test solutions, in order to maintain ionic strength $\left(0.1,0.25\right.$ and $\left.0.5 \mathrm{~mol} / \mathrm{dm}^{3}\right)$. The $\mathrm{pH}$ values of the test solution were adjusted in the range between 1 and 7 with a suitable amount of perchloric acid $\left(0.5 \mathrm{~mol} / \mathrm{dm}^{3}\right)$. The UV spectra were taken immediately after preparation of the test solutions, at room temperature. After that, the $\mathrm{pH}$ of each test solution was measured. At the same time, the blanks were prepared with the same composition as the test solutions. Three series of the test solutions were prepared, and all the measurements were performed in triplicate.

\section{Structure of investigated hydrazones}

Hydrazones possess an azomethine $-\mathrm{NHN}=\mathrm{CH}$ group, thus they are considered as derivatives of aldehydes and ketones in which the oxygen atom has been replaced by the $-\mathrm{NNH}_{2}$ functional group [25]. 
Actually, hydrazones are formed by the reaction of hydrazine or hydrazide with aldehydes and ketones in ethanol $[9,26]$. In this investigation we used five $p$-nitro- $p$-substituted benzoylhydrazones previously synthesized in our laboratory [27]. The structural and molecular formula of investigated hydrazones as well as melting points are given in Table 1.

Table 1. The chemical structure of investigated hydrazones.

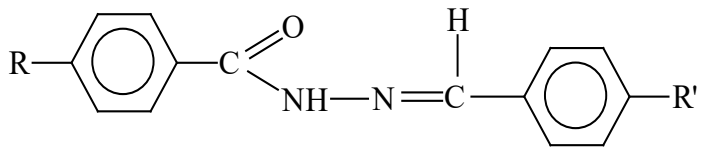

$\mathrm{R}=-\mathrm{H},-\mathrm{CH}_{3^{\prime}}-\mathrm{OCH}_{3^{\prime}}-\mathrm{Cl},-\mathrm{OH} \quad \mathrm{R}^{\prime}=-\mathrm{NO}_{2}$

\begin{tabular}{|c|c|c|c|c|}
\hline No. & Name & $\begin{array}{c}\text { Molecular } \\
\text { formula }\end{array}$ & $\begin{array}{c}\text { Molecular } \\
\text { mass [g/mol] }\end{array}$ & $\begin{array}{c}\text { Melting } \\
\text { point [ [ }{ }^{\circ} \mathbf{C} \text { ] }\end{array}$ \\
\hline $\mathbf{H}_{\mathbf{1}}$ & N- $p$-nitrobenzaldehydebenzoylhydrazone & $\mathrm{C}_{14} \mathrm{H}_{11} \mathrm{O}_{3} \mathrm{~N}_{3}$ & 269 & $236-239$ \\
\hline $\mathbf{H}_{2}$ & N- $p$-nitrobenzaldehyde- $p$-ethylbenzoylhydrazone & $\mathrm{C}_{15} \mathrm{H}_{13} \mathrm{O}_{3} \mathrm{~N}_{3}$ & 283 & $246-248.5$ \\
\hline $\mathbf{H}_{3}$ & $\mathrm{~N}-p$-nitrobenzaldehyde- $p$-etoxybenzoylhydrazone & $\mathrm{C}_{15} \mathrm{H}_{13} \mathrm{O}_{4} \mathrm{~N}_{3}$ & 299 & $243-245.5$ \\
\hline $\mathbf{H}_{4}$ & $\mathrm{~N}-p$-nitrobenzaldehyde- $p$-chlorobenzoylhydrazone & $\mathrm{C}_{14} \mathrm{H}_{10} \mathrm{O}_{3} \mathrm{~N}_{3} \mathrm{Cl}$ & 303 & $253-255$ \\
\hline $\mathbf{H}_{5}$ & $\mathrm{~N}-p$-nitrobenzaldehyde- $p$-doxybenzoylhydrazone & $\mathrm{C}_{14} \mathrm{H}_{11} \mathrm{O}_{4} \mathrm{~N}_{3}$ & 285 & $328.5-330$ \\
\hline
\end{tabular}

The investigated hydrazones were structurally characterized by UV spectroscopy, infrared spectroscopy (IR), nuclear magnetic resonance $\left({ }^{1} \mathrm{H}\right.$ NMR and $\left.{ }^{13} \mathrm{C} N \mathrm{NR}\right)$, as well as, by elemental analysis [28].

\section{$\mathrm{p} K_{\mathrm{BH}}{ }^{+}$calculations}

The dissociation constants of investigated hydrazones were calculated using the Henderson Hasselbach equation (Eq. 1) [20].

$$
\mathrm{p} K_{\mathrm{BH}}{ }^{+}=n \cdot \mathrm{pH}+\log I
$$

where, $\mathrm{p} \mathrm{BH}_{\mathrm{BH}}{ }^{+}$is the dissociation constant of the protonated form, $I$ is the ionization ratio, and $\mathrm{n}$ is number of transferred protons.

The ionization ratio $I\left(I=c\left(\mathrm{BH}^{+}\right) / c(\mathrm{~B})\right)$ is actually the ratio between the concentration of the protonated $\left(\mathrm{BH}^{+}\right)$and neutral $(\mathrm{B})$ form of the hydrazones. The calculations of ionization ratio were performed using the molar absorption coefficient values and the absorbance data obtained at four selected wavelengths. In accordance with Beer's law (Eq. 2) an over determined system of four equations (absorbance data) with two unknown parameters (concentration of neutral and protonated form) was obtained.

$$
A_{\lambda, \mathrm{i}}=l \sum_{\mathrm{i}=1}^{\mathrm{n}} c_{\mathrm{i}} \varepsilon_{\lambda_{\mathrm{i}}}
$$

Absorbance value which corresponds to the absorption maximum was used in calculations. Actually, the obtained results were more accurate when four absorbance values were used. The calculations of the $\mathrm{p} \mathrm{BH}^{+}$ values were performed from the absorbance data at four selected wavelengths around the absorption maximum that appears in neutral and acidic media. Following wavelengths were used: $\mathbf{H}_{\mathbf{1}}(258,266,324$ and $332 \mathrm{~nm}), \mathbf{H}_{\mathbf{2}}$ $(242,250,324$ and $332 \mathrm{~nm}), \mathbf{H}_{3}(258,266,330$ and $338 \mathrm{~nm}), \mathbf{H}_{4}(242,250,332$ and $324 \mathrm{~nm})$ and $\mathbf{H}_{5}(258,266$, 332 and $340 \mathrm{~nm}$ ). The obtained overdetermined system had this form (Eq. 3): 


$$
\begin{aligned}
& A \lambda_{1}=\left[\varepsilon \lambda_{1}(\mathrm{~B}) \cdot c(\mathrm{~B})+\varepsilon \lambda_{1}\left(\mathrm{BH}^{+}\right) \cdot c\left(\mathrm{BH}^{+}\right)\right] l \\
& A \lambda_{2}=\left[\varepsilon \lambda_{2}(\mathrm{~B}) \cdot c(\mathrm{~B})+\varepsilon \lambda_{2}\left(\mathrm{BH}^{+}\right) \cdot c\left(\mathrm{BH}^{+}\right)\right] l \\
& A \lambda_{3}=\left[\varepsilon \lambda_{3}(\mathrm{~B}) \cdot c(\mathrm{~B})+\varepsilon \lambda_{3}\left(\mathrm{BH}^{+}\right) \cdot c\left(\mathrm{BH}^{+}\right)\right] l \\
& A \lambda_{4}=\left[\varepsilon \lambda_{4}(\mathrm{~B}) \cdot c(\mathrm{~B})+\varepsilon \lambda_{4}\left(\mathrm{BH}^{+}\right) \cdot c\left(\mathrm{BH}^{+}\right)\right] l
\end{aligned}
$$

where, $c(\mathrm{~B})$ is the concentration of neutral form, $c\left(\mathrm{BH}^{+}\right)$is the concentration of protonated form, $\varepsilon(\mathrm{B})$ is the molar absorption coefficient of neutral form, $\varepsilon_{\lambda}\left(\mathrm{BH}^{+}\right)$is the molar absorption coefficient of protonated form. The obtained over determined system was calculated using Excel. The molar absorption coefficients were calculated in accordance with equation (4).

$$
\varepsilon \lambda, \mathrm{i}=A \lambda, \mathrm{i} / c(\mathrm{~B}) l
$$

In order to determine the molar absorption coefficients, the absorbance values of the neutral ( $\mathrm{pH} 4.5$ ) and protonated $(\mathrm{pH} \mathrm{1.4)}$ form were used. For this purpose, the UV spectra were recorded at three different concentrations $\left(2.40 \cdot 10^{-5}, 3.00 \cdot 10^{-5}\right.$ and $\left.3.60 \cdot 10^{-5} \mathrm{~mol} / \mathrm{dm}^{3}\right)$ of the investigated hydrazones in solution at ionic strengths $0.1 \mathrm{~mol} / \mathrm{dm}^{3}, 0.25 \mathrm{~mol} / \mathrm{dm}^{3}$ and $0.5 \mathrm{~mol} / \mathrm{dm}^{3}$.

The influence of the solvent can be eliminated by employing method of Characteristic Vector Analysis (CVA), which has been tested and proven to be applicable in the analysis of spectroscopic data, to investigate problems dealing with protonation [21,22]. The $\mathrm{p}_{\mathrm{BH}^{+}}{ }^{+}$values of the investigated hydrazones were determined graphically, as an intercept of the dependence of $\log I$ on $\mathrm{pH}$ [29]. When $c\left(\mathrm{BH}^{+}\right)=c(\mathrm{~B}), \log I=0$, and the graphically determined $\mathrm{p} K_{\mathrm{BH}}{ }^{+}$value is equal to the $\mathrm{pH}$ value of the solution. The thermodynamic $\mathrm{p} K_{\mathrm{BH}}{ }^{+}$values were evaluated as an intercept with extrapolation of the curve $\mathrm{p}_{\mathrm{BH}}{ }^{+}=f(\sqrt{ } \mu)$ to zero ionic strength [30].

\section{Semiempirical calculations}

There is a great interest in applying semiempirical methods to predict proton transfer at a given $\mathrm{pH}$, for different types of organic molecules. Optimization of the geometry of investigated hydrazones and calculation of total energy, binding energy, enthalpy of formation, Gibbs energies of formation, atomic charge, proton affinity values was performed using AM1 (Austin Model 1) and PM3 (Parametric Method 3) semiempirical methods $[23,31]$. These parameters were further used for prediction of protonation site, influence of the substituents in the para position in the benzene ring of investigated hydrazones, as well as the stability of the isomers $(E$ and $Z)$ and their protonated forms. Proton affinity values were calculated according to following equations:

$$
\begin{aligned}
& \mathrm{PA}=\Delta G_{f}(\mathrm{~B})+\Delta G_{f}\left(\mathrm{H}^{+}\right)-\Delta G_{f}\left(\mathrm{BH}^{+}\right) \\
& \mathrm{PA}=\Delta H_{f}^{\mathrm{o}}(\mathrm{B})+\Delta H_{f}^{\mathrm{o}}\left(\mathrm{H}^{+}\right)-\Delta H_{f}^{\mathrm{o}}\left(\mathrm{BH}^{+}\right)
\end{aligned}
$$

where, PA is the proton affinity, $\Delta H^{\circ}(\mathrm{B}) / \Delta G_{f}(\mathrm{~B})$ is the heat/Gibbs energy of formation for the molecule, $\Delta H^{\circ} f\left(\mathrm{BH}^{+}\right) / \Delta G_{f}\left(\mathrm{BH}^{+}\right)$is the heat/Gibbs energy of formation for the cation and $\Delta H^{\circ} f\left(\mathrm{H}^{+}\right) / \Delta G_{f}\left(\mathrm{H}^{+}\right)$is the heat/Gibbs energy for the proton formation and has the value of $367.2 / 362.57 \mathrm{kcal} / \mathrm{mol}$, kcal $/ \mathrm{mol}$ [32]. Theoretical calculations were carried out at the restricted Hartree-Fock level (RHF) in the HYPERCHEM program. All structures were optimized to a gradient norm of $<0.1$. 


\section{Results and discussion}

\section{Spectral behavior of $p$-nitro-p-substituted benzoylhydrazones in acidic media}

The experimental UV spectra of hydrazone N-p-nitrobenzaldehyde- $p$-etoxybenzoyl-hydrazone $\left(\mathrm{H}_{3}\right)$ obtained in perchloric acid media in the $\mathrm{pH}$ region from 1.2 to 4.9 (water:ethanol $=1: 1, V / V$ ) maintaining the ionic strength of $0.1 \mathrm{~mol} / \mathrm{dm}^{3}$ are shown in Fig. 1. Similar changes in the UV spectra of this hydrazone were noticed at 0.25 and $0.5 \mathrm{~mol} / \mathrm{dm}^{3}$ ionic strength. The spectral behavior of the other investigated hydrazones $\left(\mathbf{H}_{1}\right.$, $\mathbf{H}_{2}, \mathbf{H}_{4}$ and $\mathbf{H}_{5}$, see Table 1) at the same conditions was similar and their UV spectra are dropped out.

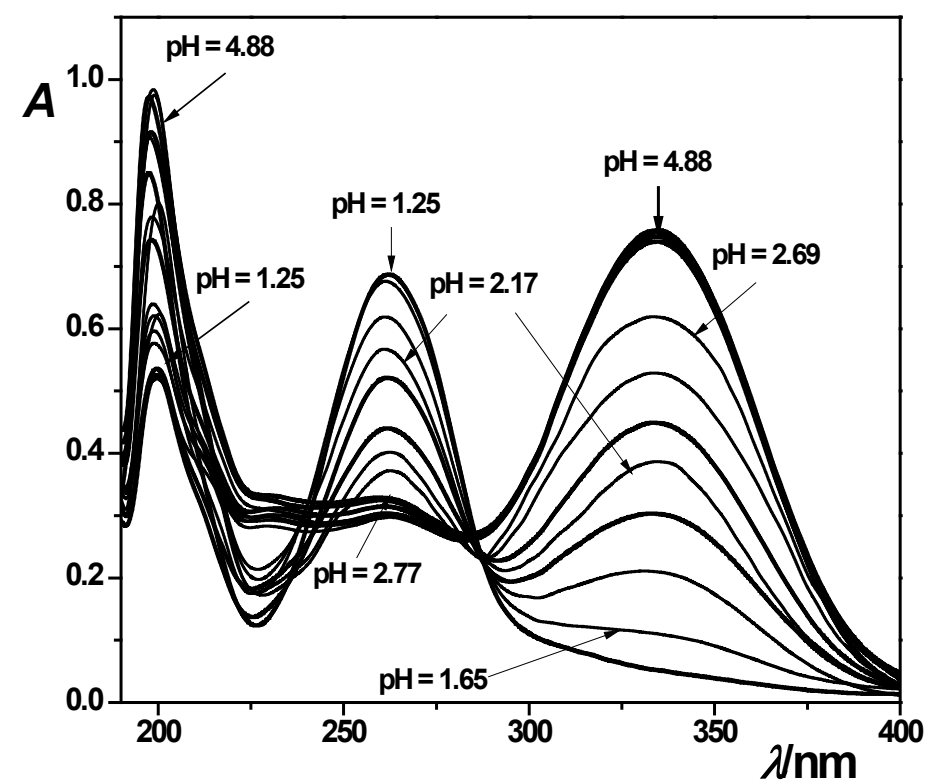

Fig. 1. UV spectra of N-p-nitrobenzaldehyde- $p$-metoxybenzoylhydrazone, $\mathbf{H}_{3}\left(c=3.00 \cdot 10^{-5} \mathrm{~mol} / \mathrm{dm}^{3}\right)$ in $\mathrm{pH}$ region between 1.25 and $4.88\left(\mu=0.1 \mathrm{~mol} / \mathrm{dm}^{3}\right)$.

From the Fig. 1 it can be seen that in the weak acid media (pH 4.9), in the UV spectra of hydrazone $\mathbf{H}_{3}$ there are two absorption bands. The first band is located at $198 \mathrm{~nm}$ wavelength, while the second one has a maximum at $330 \mathrm{~nm}$. According to the literature data the first absorption band is as a result of $\pi \rightarrow \pi^{*}$ electron transitions, mainly in the aromatic structure of the molecules [33]. The second absorption band (330 nm) is probably due to the $n \rightarrow \pi^{*}$ electron transitions [34]. Literature data revealed that when the nitrogen atom with lone electron pair is present as it is case with hydrazone nitrogen, than there is a huge probability of $n \rightarrow \pi$ electron transitions [35].

By increasing the acidity of the solution a hypochromic effect was noticed for the first absorption band $(198 \mathrm{~nm})$, while its position did not change. The first band has similar position for all investigated hydrazones suggesting that the substituents present in the investigated hydrazones have no important influence on this band. On the other hand the significant changes were observed in the intensity and the position of the second absorption band $(330 \mathrm{~nm})$. Namely, by increasing the acidity of the solutions the intensity of this band decreased and hypsochromic shift was observed. This absorption band disappeared at $\mathrm{pH}$ values less than 1.65. At the same time, in acidic media $(\mathrm{pH}<2.77)$ a new absorption band at a wavelength of $260 \mathrm{~nm}$ appeared. The intensity of this band increased, by increasing the acidity of the solution (See Fig. 1). At $\mathrm{pH}$ values lower than 2 there were no further changes in the intensity and the position of this band. The described changes in the UV spectra of hydrazone $\mathbf{H}_{3}$ are due to the reaction of protonation in acidic media. 
It can be noticed the existence of isosbestic points at 240 and $280 \mathrm{~nm}$ wavelength, in the UV spectra of the hydrazone $\mathbf{H}_{3}$ (Fig. 1), but they are not clearly defined. One reason for this can be the influence of the solvent taking into consideration that the protonation reaction is reversible i.e. the neutral and protonated form are in equilibrium in the solution. The influence of the solvent from the experimental spectra can be eliminated applying CVA method [21,22]. The reconstructed UV spectra of the hydrazone $\mathbf{H}_{3}$ at ionic strength $0.1 \mathrm{~mol} / \mathrm{dm}^{3}$ are shown in the Fig. 2.

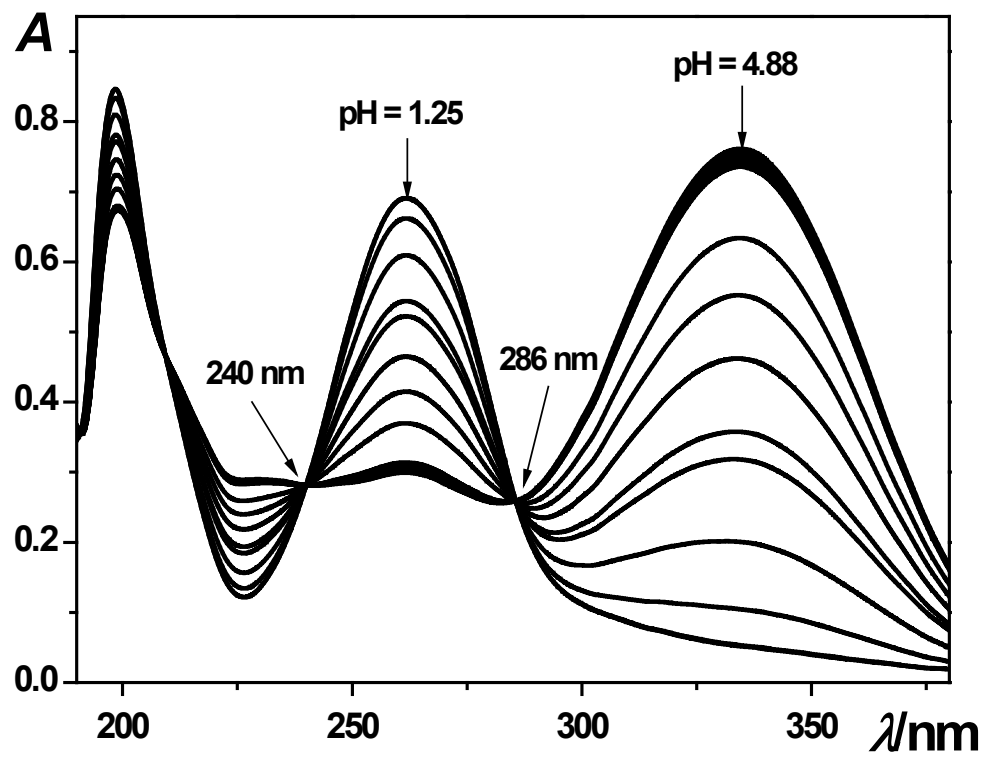

Fig. 2. Reconstructed UV spectra of N-p-nitrobenzaldehyde- $p$-metoxybenzoylhydrazone, $\mathbf{H}_{3}\left(c=3.00 \cdot 10^{-5}\right.$ $\left.\mathrm{mol} / \mathrm{dm}^{3}\right), \mu=0.1 \mathrm{~mol} / \mathrm{dm}^{3}$.

In the reconstructed spectra it can be observed well defined isosbestic point at 240 and $285 \mathrm{~nm}$. The existence of isosbestic points additionally confirmed that in the solution there are two forms (neutral and protonated) of investigated hydrazones. The exact position of the absorption bands (neutral and protonated form) of investigated hydrazones $\left(\mathbf{H}_{1}-\mathbf{H}_{5}\right)$, as well as $\mathrm{pH}$ region of protonation is listed in Table 2.

Table 2. Wavelengths of the absorption maxima of hydrazones $\mathbf{H}_{1}-\mathbf{H}_{5}$ in acidic media, and $\mathrm{pH}$ range of protonation.

\begin{tabular}{|c|c|c|c|c|c|}
\hline \multirow{2}{*}{ Hydrazone } & \multicolumn{2}{|c|}{ neutral form } & \multicolumn{2}{c|}{ protonated form } & \multirow{2}{*}{$\begin{array}{c}\text { pH range of } \\
\text { protonation }\end{array}$} \\
\cline { 2 - 5 } & $\mathbf{p H}$ & $\boldsymbol{\lambda}_{\mathbf{2} \max }$ & $\mathbf{p H}$ & $\boldsymbol{\lambda}_{\mathbf{2} \max }$ & $1.4-2.7$ \\
\hline $\mathbf{H}_{\mathbf{1}}$ & 4.77 & 328 & 1.33 & 262 & $1.6-2.7$ \\
\hline $\mathbf{H}_{\mathbf{2}}$ & 4.65 & 330 & 1.47 & 246 & $1.6-2.7$ \\
\hline $\mathbf{H}_{\mathbf{3}}$ & 4.88 & 334 & 1.51 & 262 & $1.6-2.9$ \\
\hline $\mathbf{H}_{\mathbf{4}}$ & 4.83 & 328 & 1.41 & 246 & $1.6-2.9$ \\
\hline $\mathbf{H}_{\mathbf{5}}$ & 4.91 & 336 & 1.41 & 262 & \\
\hline
\end{tabular}


The results presented in Table 2 demonstrated that by increasing the acidity of the solutions, the absorption band which appeared at $330 \mathrm{~nm}$ shifted from $66 \mathrm{~nm}\left(\mathbf{H}_{\mathbf{1}}\right.$ and $\left.\mathbf{H}_{5}\right)$ to $84 \mathrm{~nm}\left(\mathbf{H}_{2}\right)$ i.e. towards shorter wavelengths. The $\mathrm{pH}$ region of protonation shows that there are no important differences in the acid-base behavior of investigated hydrazones in acidic media (Table 2). The dependence of the absorbance values on $\mathrm{pH}$ of the solution for investigated hydrazones $\left(\mathbf{H}_{1}-\mathbf{H}_{5}\right)$ at $0.1 \mathrm{~mol} / \mathrm{dm}^{3}$ ionic strength are given in Fig. 3.

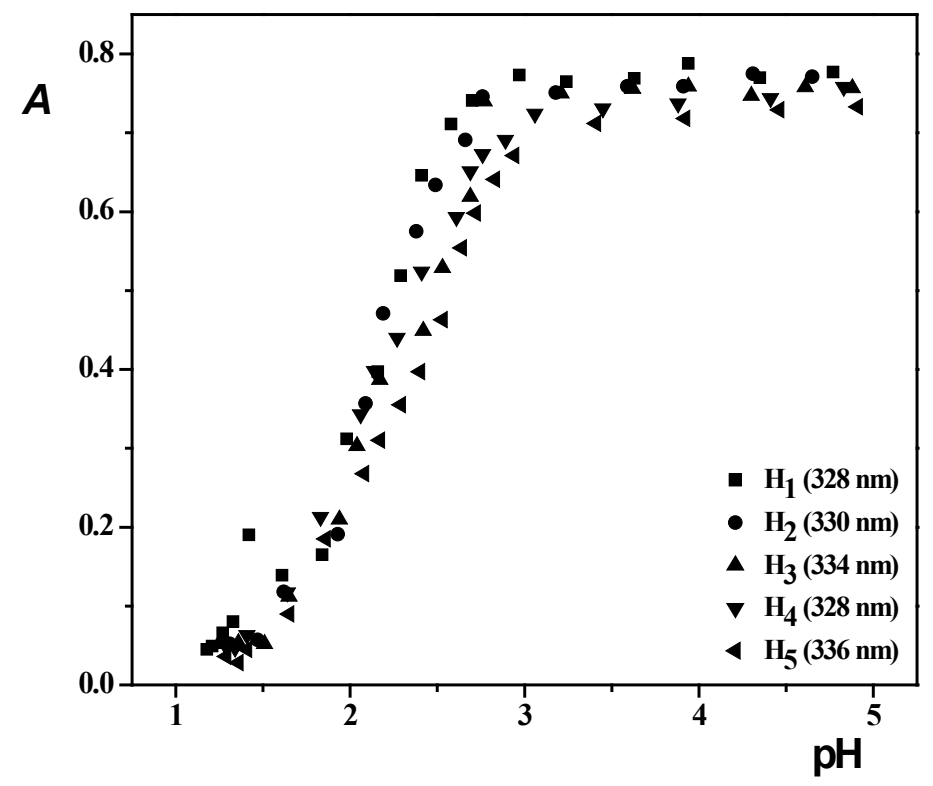

Fig. 3. Dependence of absorbance on $\mathrm{pH}$ of the solution $\left(\mu=0.1 \mathrm{~mol} / \mathrm{dm}^{3}\right)$ of hydrazones $\mathbf{H}_{1}-\mathbf{H}_{5}$

The dependence of the absorbance on $\mathrm{pH}$ of the solution has sigmoidal shape with one plateau indicating that the protonation reaction took place in one step. The upper plateau corresponds to the absorption of the neutral form which exists in the solution. As a result of protonation process the absorbance values decreased when the acidity of the solution increased. There were no noticed changes in the absorbance values, with the further changes in the acidity of the solution $(\mathrm{pH} \leq 1.5)$. At this $\mathrm{pH}$ only the protonated form of the compounds is present in the solution. The substituents present in the molecule of the investigated hydrazones have not significant influence on the protonation process, presented with Scheme 1 [36]:

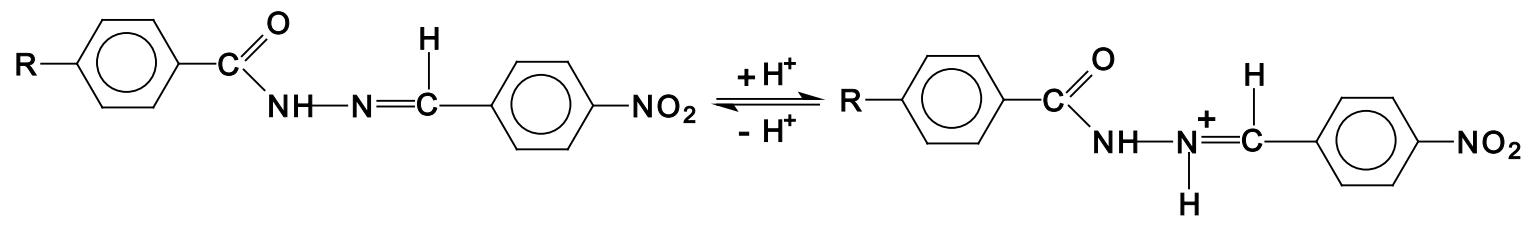

Scheme 1. Protonation process of investigated hydrazones.

\section{Semiempirical data}

The influence of the nitro group present in the hydrazone molecule on the protonation site, was investigated by means of semiempirical calculation applying AM1 and PM3 methods. The obtained values of Gibbs energy of formation, enthalpy of formation and proton affinity values are listed in Table 3. 
Table 3. Gibbs energy of formation $\left(\Delta G_{f}\right)$, enthalpy of formation $\left(\Delta H_{f}\right)$ and proton affinity (PA) of neutral (B) and protonated $\left(\mathrm{BH}^{+}\right)$form $\left(N-s p^{2}\right.$ and $N$-sp $p^{3}$ hybridized nitrogen atoms) of hydrazones $\left(\mathbf{H}_{1}-\mathbf{H}_{5}\right)$ calculated by AM1 and PM3 semiempirical methods.

\begin{tabular}{|c|c|c|c|c|c|}
\hline \multirow{2}{*}{\multicolumn{2}{|c|}{ Hydrazone }} & \multicolumn{2}{|c|}{ AM1 } & \multicolumn{2}{|c|}{ PM3 } \\
\hline & & \multirow{2}{*}{$\begin{array}{c}\begin{array}{c}\Delta \boldsymbol{G}_{\boldsymbol{f}} \\
\text { [kcal} / \mathbf{m o l}]\end{array} \\
24.78 \\
\end{array}$} & \multirow{2}{*}{$\begin{array}{c}\begin{array}{c}\Delta \boldsymbol{H}_{f} \\
{[\mathrm{kcal} / \mathrm{mol}]}\end{array} \\
64.66 \\
\end{array}$} & \multirow{2}{*}{$\begin{array}{c}\begin{array}{c}\Delta \boldsymbol{G}_{\boldsymbol{f}} \\
{[\mathrm{kcal} / \mathrm{mol}]}\end{array} \\
6.39 \\
\end{array}$} & \multirow{2}{*}{$\begin{array}{c}\begin{array}{c}\Delta \boldsymbol{H}_{\boldsymbol{f}} \\
\text { [kcal} / \mathbf{m o l}]\end{array} \\
46.57 \\
\end{array}$} \\
\hline \multirow{5}{*}{ B } & 1 & & & & \\
\hline & 2 & 15.53 & 56.69 & -8.25 & 35.79 \\
\hline & 3 & -17.72 & 25.96 & -39.93 & 6.88 \\
\hline & 4 & 16.37 & 58.24 & 1.847 & 40.32 \\
\hline & 5 & 21.57 & 19.85 & -40.81 & 0.8205 \\
\hline \multirow{5}{*}{$\begin{array}{c}\mathrm{BH}^{+} \\
\left(N-s p^{2}\right)\end{array}$} & 1 & 189.50 & 230.33 & 171.47 & 213.85 \\
\hline & 2 & 182.77 & 221.93 & 161.76 & 203.37 \\
\hline & 3 & 149.06 & 190.55 & 125.15 & 172.51 \\
\hline & 4 & 185.97 & 225.70 & 166.10 & 208.36 \\
\hline & 5 & 146.10 & 15.32 & 125.48 & 167.08 \\
\hline \multirow{5}{*}{$\begin{array}{c}\mathrm{BH}^{+} \\
\left(N-s p^{3}\right)\end{array}$} & 1 & 203.43 & 242.05 & 183.91 & 222.47 \\
\hline & 2 & 192.73 & 232.84 & 174.34 & 211.65 \\
\hline & 3 & 159.36 & 201.08 & 138.62 & 181.53 \\
\hline & 4 & 196.77 & 237.45 & 173.25 & 217.06 \\
\hline & 5 & 156.14 & 196.28 & 132.35 & 175.29 \\
\hline & & $\begin{array}{c}\mathrm{PA}\left(H_{f}\right) \\
{[\mathrm{kcal} / \mathrm{mol}]}\end{array}$ & $\begin{array}{c}\operatorname{PA}\left(G_{f}\right) \\
{[\mathrm{kcal} / \mathrm{mol}]}\end{array}$ & $\begin{array}{c}\mathrm{PA}\left(H_{f}\right) \\
{[\mathrm{kcal} / \mathrm{mol}]}\end{array}$ & $\begin{array}{c}\operatorname{PA}\left(G_{f}\right) \\
{[\mathrm{kcal} / \mathrm{mol}]}\end{array}$ \\
\hline \multirow{5}{*}{$\begin{array}{c}\mathrm{BH}^{+} \\
\left(N-s p^{2}\right)\end{array}$} & 1 & 201.48 & 194.57 & 199.86 & 197.84 \\
\hline & 2 & 201.91 & 195.32 & 199.57 & 192.55 \\
\hline & 3 & 202.56 & 195.78 & 197.76 & 197.48 \\
\hline & 4 & 199.69 & 192.96 & 199.11 & 188.31 \\
\hline & 5 & 201.68 & 194.89 & 200.89 & 196.27 \\
\hline \multirow{5}{*}{$\begin{array}{c}\mathrm{BH}^{+} \\
\left(N-s p^{3}\right)\end{array}$} & 1 & 189.76 & 184.19 & 191.24 & 183.91 \\
\hline & 2 & 191.00 & 185.36 & 191.29 & 179.97 \\
\hline & 3 & 192.03 & 185.48 & 178.74 & 174.01 \\
\hline & 4 & 187.94 & 182.16 & 190.41 & 181.16 \\
\hline & 5 & 190.72 & 184.85 & 192.68 & 189.40 \\
\hline
\end{tabular}

Comparing the proton affinity values calculated using AM1 and PM3 methods (see Table 3 ) it can be seen that the probable protonation site (higher proton affinity values) in the molecule of investigated hydrazone is $s p^{2}$ hybridized nitrogen atom. The PA values are lower for hydrazone $\mathrm{H}_{4}$ in comparison with PA values of other investigated hydrazones. This indicated that presence of the chlorine atom in the hydrazone molecule $\left(\mathbf{H}_{4}\right)$ causes a decrease in the affinity of $s p^{2}$ nitrogen atom toward proton. The proton affinity values also suggested that the protonation reaction can be written according to Scheme 1 .

In order to predict the stability of the $Z$ and $E$ isomers the values of total energy and proton affinity were compared. The calculation of proton affinity was made by the equation (6) given in the experimental part in accordance with AM1 semiempirical method. The obtained values are given in Table 4. 
Table 4. Total energy $\left(E_{\mathrm{tot}}\right)$, enthalpy of formation $\left(\Delta H_{f}\right)$ and proton affinity (PA) of neutral (B) and $s p^{2}$ protonated form $\left(\mathrm{BH}^{+}\right)$of hydrazones $\left(\mathbf{H}_{1}-\mathbf{H}_{5}\right)$ estimated by AM1 semiempirical method.

\begin{tabular}{|c|c|c|c|c|c|}
\hline \multirow{2}{*}{ Hydrazone } & \multicolumn{2}{|c|}{ neutral form } & \multicolumn{2}{|c|}{$s p^{2}$ protonated form } & \multirow{2}{*}{$\mathbf{P A}$} \\
\hline & $E_{\text {tot }}$ & $\Delta \boldsymbol{H}_{f}$ & $E_{\text {tot }}$ & $\Delta H_{f}$ & \\
\hline \multirow[b]{2}{*}{1} & -81186.68 & 65.27 & -81336.60 & 230.28 & 202.14 \\
\hline & -81176.64 & 75.31 & -81336.87 & 229.99 & 212.47 \\
\hline \multirow{2}{*}{2} & -84784.45 & 54.34 & -84932.66 & 221.04 & 200.45 \\
\hline & -84781.48 & 57.31 & -84932.42 & 221.28 & 203.18 \\
\hline \multirow{2}{*}{3} & -92162.06 & 25.87 & -92318.42 & 184.43 & 208.59 \\
\hline & -92159.33 & 28.61 & -92316.91 & 185.94 & 209.82 \\
\hline \multirow{2}{*}{4} & -88490.43 & 58.87 & -89639.14 & 225.06 & 200.96 \\
\hline & -89480.42 & 68.87 & -89639.36 & 224.84 & 211.18 \\
\hline \multirow{2}{*}{5} & -88580.60 & 20.50 & -88730.45 & 185.03 & 202.62 \\
\hline & -88570.51 & 30.59 & -89731.20 & 184.83 & 212.91 \\
\hline
\end{tabular}

The total energy values demonstrated that the $Z$ isomer has a little bit higher total energy values. This means that the $Z$ isomer is slightly more stable in neutral media in comparison with the $E$ isomer. The situation is different in acidic media where the cation is formed due to protonation of $s p^{2}$ hybridized nitrogen atom. Namely, in acidic media there is no difference in the total energy values i.e. in the stability of the $Z$ and $E$ isomers. From the Table 4 it can be seen that the $E$ isomer has higher PA values compared to $Z$ isomer. This suggested that the $E$ isomer can be easily protonated in acidic media.

\section{Dissociation constants of protonated form, $\mathrm{p} \mathrm{K}_{\mathrm{BH}}{ }^{+}$}

Stoichiometric $\mathrm{p} \mathrm{B}_{\mathrm{BH}}{ }^{+}$values of $\mathrm{N}$ - $p$-nitrobenzaldehyde- $p$-substituted benzoylhydrazones $\left(\mathbf{H}_{1}-\mathbf{H}_{5}\right)$ calculated from the absorbance values of the experimental and reconstructed spectra at ionic strength of 0.1 , 0.25 and $0.5 \mathrm{~mol} / \mathrm{dm}^{3}$ are listed in Tables 5 and 6 , respectively. Statistical data (standard deviation (SD), relative standard deviation (RSD), coefficient of determination $\left(R^{2}\right)$ ) and the range in which the obtained results are placed with confidence level of $0.05(95 \%)$ are also given in Tables 5 and 6 . The graphically obtained dissociation constants and the thermodynamic dissociation constants are presented in the Tables 5 and 6 , as well. The dissociation constants values were obtained graphically, as an intercept from the dependence of $\log I$ on $\mathrm{pH}$ of the solution (Fig. 4).

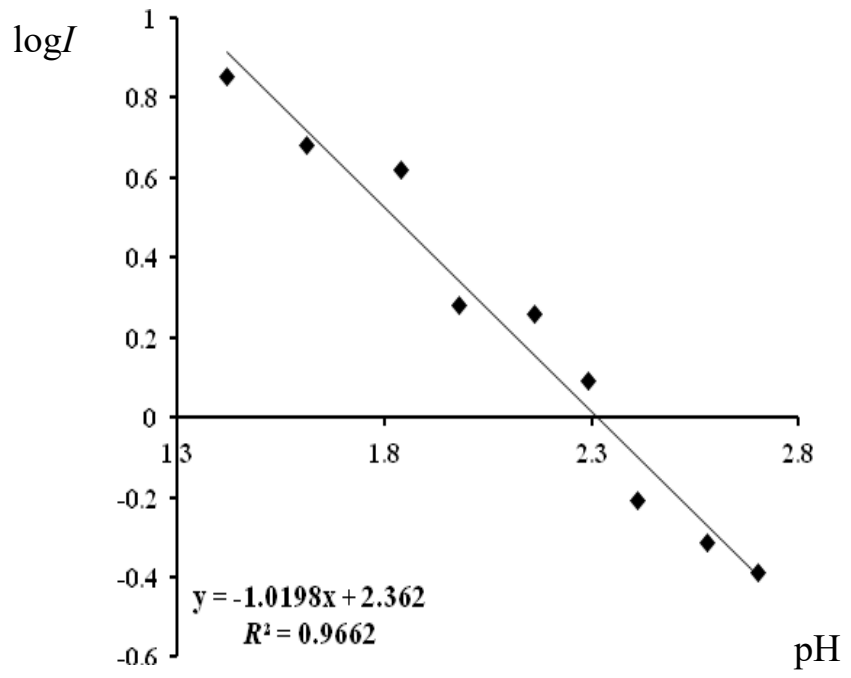

Fig. 4. Dependence of $\log I$ on $\mathrm{pH}$ for N-p-nitrobenzaldehyde- $p$-metoxybenzoylhydrazone, $\mathbf{H}_{\mathbf{1}}\left(c=3.00 \cdot 10^{-5}\right.$ $\left.\mathrm{mol} / \mathrm{dm}^{3}\right), \mu=0.1 \mathrm{~mol} / \mathrm{dm}^{3}$. 
The thermodynamic dissociation constant (table 3 and 4) were evaluated as an intercept from the dependence $\mathrm{p} K_{\mathrm{BH}}{ }^{+}=f(\sqrt{\boldsymbol{\mu}})$, with extrapolation to zero ionic strength [37, 38]. For illustration, the way of determination of thermodynamic dissociation constants for hydrazone $\mathbf{H}_{\mathbf{1}}$ is given in Fig. 5.

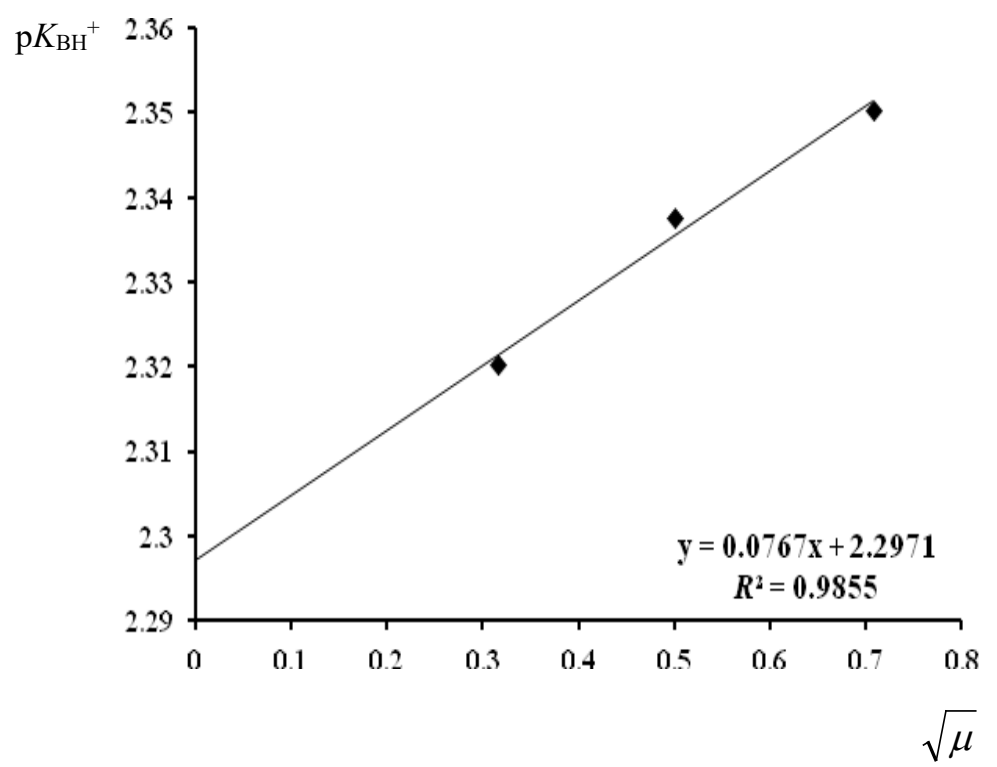

Fig. 5. The dependence of $\mathrm{p}_{\mathrm{BH}^{+}}{ }^{+}$on $\sqrt{\boldsymbol{\mu}}$ for $\mathrm{N}-p$-nitrobenzaldehyde- $p$-metoxybenzoylhydrazone $\left(\mathbf{H}_{1}, c=\right.$ $3.00 \cdot 10^{-5} \mathrm{~mol} / \mathrm{dm}^{3}$ )

The dependence $\mathrm{p} K_{\mathrm{BH}}{ }^{+}=f(\sqrt{\boldsymbol{\mu}})$ can be used for water solution as well as for solution where the volume ratio of ethanol is $50 \%$.

Table 5. Dissociation constant values (stoichiometric, graphically, thermodynamic) and statistical data (standard deviation (SD), relative standard deviation (RSD), coefficient of determination $\left(R^{2}\right)$ ), experimental spectra

\begin{tabular}{|c|c|c|c|c|c|c|c|}
\hline & $\mu$ & \multirow[b]{2}{*}{$\mathbf{n}$} & \multicolumn{3}{|c|}{ numerically } & \multicolumn{2}{|c|}{ graphically } \\
\hline & $\begin{array}{c}{[\mathbf{m o l} / \mathbf{d}} \\
\left.\mathbf{m}^{3}\right]\end{array}$ & & $\mathrm{pK}_{\mathrm{BH}}{ }^{+}$ & SD & RSD & $\mathrm{pK}_{\mathrm{BH}}{ }^{+}$ & $R^{2}$ \\
\hline \multirow{4}{*}{$\mathbf{H}_{1}$} & 0.1 & 9 & $2.32( \pm 0.05)$ & 0.08 & 3.59 & 2.36 & 0.966 \\
\hline & 0.25 & 9 & $2.33( \pm 0.03)$ & 0.05 & 2.20 & 2.38 & 0.986 \\
\hline & 0.5 & 9 & $2.35( \pm 0.04)$ & 0.07 & 2.86 & 2.41 & 0.976 \\
\hline & \multicolumn{2}{|c|}{${ }^{*} \mathrm{p} K_{\mathrm{BH}^{+}}{ }^{\left(R^{2}\right)}$} & \multicolumn{3}{|c|}{$2.29(0.985)$} & \multicolumn{2}{|c|}{$\mathbf{2 . 3 2}(0.999)$} \\
\hline \multirow{4}{*}{$\mathbf{H}_{2}$} & 0.1 & 8 & $2.58( \pm 0.02)$ & 0.03 & 1.16 & 2.59 & 0.994 \\
\hline & 0.25 & 8 & $2.60( \pm 0.03)$ & 0.05 & 1.96 & 2.62 & 0.984 \\
\hline & 0.5 & 8 & $2.62( \pm 0.02)$ & 0.04 & 1.49 & 2.65 & 0.990 \\
\hline & \multicolumn{2}{|c|}{${ }^{*} \mathrm{p} K_{\mathrm{BH}^{+}}{ }^{\left(R^{2}\right)}$} & \multicolumn{3}{|c|}{$2.55(0.974)$} & \multicolumn{2}{|c|}{$\mathbf{2 . 5 5}(0.989)$} \\
\hline \multirow{4}{*}{$\mathbf{H}_{3}$} & 0.1 & 8 & $2.46( \pm 0.04)$ & 0.07 & 2.73 & 2.42 & 0.970 \\
\hline & 0.25 & 8 & $2.46( \pm 0.05)$ & 0.07 & 2.86 & 2.43 & 0.970 \\
\hline & 0.5 & 8 & $2.49( \pm 0.06)$ & 0.09 & 3.66 & 2.45 & 0.952 \\
\hline & \multicolumn{2}{|c|}{${ }^{*} \mathrm{p} K_{\mathrm{BH}}{ }^{+}\left(R^{2}\right)$} & \multicolumn{3}{|c|}{$2.42(0.937)$} & \multicolumn{2}{|c|}{$\mathbf{2 . 3 9}(0.926)$} \\
\hline
\end{tabular}




\begin{tabular}{|c|c|c|c|c|c|c|c|}
\hline \multirow{4}{*}{$\mathbf{H}_{4}$} & 0.1 & 10 & $2.07( \pm 0.03)$ & 0.04 & 2.06 & 2.17 & 0.990 \\
\hline & 0.25 & 10 & $2.09( \pm 0.03)$ & 0.05 & 2.46 & 2.21 & 0.988 \\
\hline & 0.5 & 10 & $2.11( \pm 0.03)$ & 0.05 & 2.57 & 2.27 & 0.990 \\
\hline & \multicolumn{2}{|c|}{${ }^{*} \mathrm{p} K_{\mathrm{BH}}{ }^{+}\left(R^{2}\right)$} & \multicolumn{3}{|c|}{$\mathbf{2 . 0 5}(0.999)$} & \multicolumn{2}{|c|}{$\mathbf{2 . 0 8}(0.999)$} \\
\hline \multirow{4}{*}{$\mathbf{H}_{5}$} & 0.1 & 11 & $2.34( \pm 0.03)$ & 0.06 & 2.38 & 2.35 & 0.980 \\
\hline & 0.25 & 11 & $2.45( \pm 0.06)$ & 0.09 & 3.71 & 2.44 & 0.948 \\
\hline & 0.5 & 11 & $2.51( \pm 0.04)$ & 0.07 & 2.78 & 2.53 & 0.970 \\
\hline & \multicolumn{2}{|c|}{${ }^{*} \mathrm{p} K_{\mathrm{BH}}{ }^{+}\left(R^{2}\right)$} & \multicolumn{3}{|c|}{$2.22(0.969)$} & \multicolumn{2}{|c|}{$\mathbf{2 . 2 2}(0.996)$} \\
\hline
\end{tabular}

" $\mathrm{K}_{\mathrm{BH}}{ }^{+}$- thermodynamic dissociation constants, $\mu$ - ionic strength, $\mathrm{n}$ - number of measurements.

Table 6. Dissociation constant values (stoichiometric, graphically, thermodynamic) and statistical data (standard deviation (SD), relative standard deviation (RSD), coefficient of determination $\left(R^{2}\right)$ ), reconstructed spectra.

\begin{tabular}{|c|c|c|c|c|c|c|c|}
\hline & $\mu$ & \multirow{2}{*}{$\mathbf{n}$} & \multicolumn{3}{|c|}{ numerically } & \multicolumn{2}{|c|}{ graphically } \\
\hline & {$\left[\mathrm{mol} / \mathrm{dm}^{3}\right]$} & & $\mathrm{pK}_{\mathrm{BH}^{+}}$ & SD & RSD & $\mathrm{pK}_{\mathrm{BH}}^{+}$ & $R^{2}$ \\
\hline \multirow{4}{*}{$\mathbf{H}_{1}$} & 0.1 & 9 & $2.26( \pm 0.06)$ & 0.09 & 4.31 & 2.18 & 0.948 \\
\hline & 0.25 & 9 & $2.27( \pm 0.05)$ & 0.07 & 3.89 & 2.18 & 0.966 \\
\hline & 0.5 & 9 & $2.29( \pm 0.06)$ & 0.09 & 4.08 & 2.22 & 0.948 \\
\hline & \multicolumn{2}{|c|}{${ }^{*} \mathrm{p} K_{\mathrm{BH}}{ }^{+}\left(R^{2}\right)$} & \multicolumn{3}{|c|}{$\mathbf{2 . 2 3}(0.944)$} & \multicolumn{2}{|c|}{$2.15(0.941)$} \\
\hline \multirow{4}{*}{$\mathbf{H}_{2}$} & 0.1 & 8 & $2.35( \pm 0.07)$ & 0.10 & 4.29 & 2.38 & 0.935 \\
\hline & 0.25 & 8 & $2.41( \pm 0.05)$ & 0.07 & 3.18 & 2.40 & 0.964 \\
\hline & 0.5 & 8 & $2.45( \pm 0.05)$ & 0.08 & 3.29 & 2.41 & 0.960 \\
\hline & \multicolumn{2}{|c|}{${ }^{*} \mathrm{p} K_{\mathrm{BH}}{ }^{+}\left(R^{2}\right)$} & \multicolumn{3}{|c|}{$\mathbf{2 . 2 9}(0.998)$} & \multicolumn{2}{|c|}{$\mathbf{2 . 3 5}(0.963)$} \\
\hline \multirow{4}{*}{$\mathbf{H}_{3}$} & 0.1 & 8 & $2.36( \pm 0.03)$ & 0.05 & 2.12 & 2.31 & 0.984 \\
\hline & 0.25 & 8 & $2.40( \pm 0.06)$ & 0.08 & 3.65 & 2.32 & 0.952 \\
\hline & 0.5 & 8 & $2.43( \pm 0.06)$ & 0.09 & 3.67 & 2.35 & 0.954 \\
\hline & \multicolumn{2}{|c|}{${ }^{*} \mathrm{p} K_{\mathrm{BH}}{ }^{+}\left(R^{2}\right)$} & \multicolumn{3}{|c|}{$\mathbf{2 . 3 1}(0.995)$} & \multicolumn{2}{|c|}{$2.27(0.969)$} \\
\hline \multirow{4}{*}{$\mathbf{H}_{4}$} & 0.1 & 10 & $2.27( \pm 0.02)$ & 0.03 & 1.48 & 2.33 & 0.994 \\
\hline & 0.25 & 10 & $2.28( \pm 0.06)$ & 0.08 & 3.92 & 2.39 & 0.964 \\
\hline & 0.5 & 10 & $2.30( \pm 0.04)$ & 0.05 & 2.53 & 2.41 & 0.984 \\
\hline & \multicolumn{2}{|c|}{${ }^{*} \mathrm{p} K_{\mathrm{BH}}{ }^{+}\left(R^{2}\right)$} & \multicolumn{3}{|c|}{$\mathbf{2 . 2 4}(0.995)$} & \multicolumn{2}{|c|}{$\mathbf{2 . 1 7}(0.838)$} \\
\hline \multirow{4}{*}{$\mathbf{H}_{5}$} & 0.1 & 11 & $2.26( \pm 0.04)$ & 0.07 & 3.24 & 2.25 & 0.968 \\
\hline & 0.25 & 11 & $2.28( \pm 0.06)$ & 0.09 & 4.25 & 2.30 & 0.942 \\
\hline & 0.5 & 11 & $2.29( \pm 0.07)$ & 0.11 & 4.66 & 2.38 & 0.935 \\
\hline & \multicolumn{2}{|c|}{${ }^{*} \mathrm{p} K_{\mathrm{BH}}{ }^{+}\left(R^{2}\right)$} & \multicolumn{3}{|c|}{$\mathbf{2 . 2 5}(0.997)$} & \multicolumn{2}{|c|}{$\mathbf{2 . 1 4}(0.991)$} \\
\hline
\end{tabular}

"p $\mathrm{KBH}^{+}$- thermodynamic dissociation constants, $\mu$ - ionic strength, $\mathrm{n}$ - number of measurements.

There are no significant differences in the values of stoichiometric dissociation constants of all investigated hydrazones $\left(\mathbf{H}_{1}-\mathbf{H}_{5}\right)$. The calculated $\mathrm{p} K_{\mathrm{BH}^{+}}{ }^{+}$values are identical to those graphically obtained (See Tables 5 and 6). This means that dissociation constants can be successfully determined, in the both ways. This was also confirmed with the results of the t-test i.e. the value of t-parameter $(-0.05)$ was below critical value (2.306) of this parameter. At the same time, there were no important differences in the $\mathrm{p} \mathrm{BH}^{+}$values determined from the absorbance data of the experimental UV spectra with those determined from the absorbance data of the reconstructed spectra (See Tables 5 and 6). By increasing the value of the ionic strength, the $\mathrm{p} K_{\mathrm{BH}}{ }^{+}$values slightly increased which is in accordance with the theoretical expectations. 
By comparison of thermodynamic dissociation constants it can be seen that the values ranged from 2.05 for hydrazone $\mathbf{H}_{4}$ to 2.55 for hydrazone $\mathbf{H}_{2}$. The following order of thermodynamic $\mathrm{p} K_{\mathrm{BH}}{ }^{+}$values was observed (Table 5):

\begin{tabular}{cccccc|}
\hline Hydrazone: & $\mathbf{H}_{\mathbf{4}}$ & $\mathbf{H}_{\mathbf{5}}$ & $\mathbf{H}_{\mathbf{1}}$ & $\mathbf{H}_{\mathbf{3}}$ & $\mathbf{H}_{\mathbf{2}}$ \\
$\mathrm{p} K_{\mathrm{BH}+}$ & 2.05 & 2.22 & 2.29 & 2.42 & 2.55 \\
& the strength of the protonated base decreases \\
\hline
\end{tabular}

The hydrazones $\mathbf{H}_{4}(-\mathrm{Cl})$ and $\mathbf{H}_{5}(-\mathrm{OH})$ have a little lower $\mathrm{p} K_{\mathrm{BH}}{ }^{+}$values i.e. theirs protonated forms are stronger acids compared with hydrazones $\mathbf{H}_{1}-\mathbf{H}_{3}$. This is probably due to the influence of the present substituents in the molecule. Actually, the protonated form of hydrazone $\mathbf{H}_{\mathbf{4}}$ which has chlorine atom in para position of benzene ring is the strongest acid compared with other investigated hydrazones. The weakest acid is hydrazone $\mathbf{H}_{2}\left(-\mathrm{CH}_{3}\right)$.

\section{Conclusion}

The spectral behavior of five $p$-nitro- $p$-substituted hydrazones was investigated in perchloric acid media, using the methods of UV spectroscopy. The changes in the UV spectra indicated that protonation reaction occurred in acidic media. The dependence of absorbance on $\mathrm{pH}$ indicated that the protonation process took place in one step. The influence of the solvent $(50 \%$ ethanol) was eliminated using the method of characteristic vector analysis (CVA). The changes in the UV spectra were used for calculation of dissociation constants. The $\mathrm{p} \mathrm{BBH}^{+}$values were determined numerically and graphically. In order to determine the thermodynamic dissociation constants the measurements were performed at three different ionic strengths $(0.1$, 0.25 and $0.5 \mathrm{~mol} / \mathrm{dm}^{3}$ ). It should be emphasized that there are no big differences in the $\mathrm{p} K_{\mathrm{BH}}{ }^{+}$values of all investigated hydrazones suggesting that the substituents $\left(-\mathrm{H},-\mathrm{CH}_{3},-\mathrm{OCH}_{3},-\mathrm{Cl}\right.$ and $\left.-\mathrm{OH}\right)$ have no significant influence. The proton affinity values indicated that the probable protonation site in the molecule of investigated hydrazone is $s p^{2}$ hybridized nitrogen atom, and the $E$ isomer can be easily protonated. The $Z$ isomer is slightly more stable in comparison with the $E$ isomer in neutral media, while in acidic media there is no difference in stability of the $Z$ and $E$ isomers.

\section{References}

1. Brehme, R.; Enders, D.; Fernandez R.; Lassaletta, J. M. Eur. J. Org. Chem. 2007, 34, 5629-5660.

2. Belskaya, N. P.; Dehaen W.; Bakulev, V. A. ARKIVOC, 2010, (i), 275-332.

3. Banerjee, S.; Mondal, S.; Chakraborty, W.; Sen, S.; Gachhui, R.; Butcher, R. J.; Slawin, A. M. Z.; Mandal C.; Mitra, S. Polyhedron, 2009, 28(13), 2785-2793.

4. Mao, J.; Wang, Y.; Wan, B.; Kozikowski A. P.; Franzblau, S. G. Chem. Med. Chem. 2007, 2(11), 1624-1630.

5. Ali, Md. R.; Marella, A.; Alam, Md. T.; Naz, R.; Akhter, M.; Shaquiquzzaman, Md.; Saha R.; Tanwar, O.; Alam Md. M.; Hooda, J. Indonesian J. Pharm., 2012, 23, 193-202.

6. Kumar, P.; Rai, A.; Singh, M.; Kumar, D.; Sahdev A. K.; Raj V. EC Pharm. Sci. 2016, 23, 278 (2016).

7. Kumar, N.; Chauhan, L. S.; Dashora N.; Sharma, C. S. Sch. Acad. J. Pharm., 2014, 3(5), 366-373.

8. Padmini, K.; Jaya Preethi, P.; Divya, M.; Rohini, P.; Lohita, M. Swetha K. Kaladar, P. Int. J Pharm. Res. \& Rev. 2013, 2(8), 43-58.

9. Rollas S.; Küçükgüzel, S.G. Molecules, 2017, 12, 1910-1939.

10. Singh, R. B.; Jain P.; Singh, R. P. Talanta, 1982, 29, 77-84.

11. Suvarapu, L. N.; Seo1, Y. K.; Baek S. O.; Ammireddy, V. R. E-Journal of Chemistry, 2012, 9(3), 1288-1304. 
12. Naskar, S.; Naskar, S.; Mondal, S.; Majhi, P. K.; Drew M. G. B.; Chattopadhyay, S. K. Inorg. Chim. Acta, 2011, 371, 100-106.

13. Singh M.; Raghav, N. Int. J. Pharm. Pharm. Sci. 2011, 3(4), 26-32.

14. Avila Terra, L. H. S.; da Cunha Areias M. C.; Gaubeur, I.; Encarnacion M.; Suarez-iha V. Spectros. Lett. 1999, 32, 257-271.

15. Mohan, M.; Gupta, M. P.; Chandra L.; Jha, N. K. Inorg. Chim. Acta, 1988, 151, 61-68

16. Aggarwal, N.; Kumar, R.; Srivastva, C.; Dureja P.; Khurana, J. M. J. Agric. Food Chem. 2010, 58, 2056-3061.

17. Liu, M.; Wang, Y.; Wangyang, W. S. Z.; Liu, F.; Cui Y. L.; Duan, Y. S. J Agric Food Chem. 2010, 58, 6859-6863.

18. Pathare, B.; Tambe, V.; Dhole S.; Patil, V. Int. J. Pharm. 2014, 4(1), 278-285.

19. Beckett A. H.; Stenlake, J. B. Practical pharmaceutical chemistry. 4th Edition - part one, CBS publishers and distributors PVT LTD, New Delhi, 1997, 88-120.

20. Brahmankar D. M.; Jaiswal, S. B. Biopharmaceutics \& pharmacokinetics. 2nd Ed., Vallabh prakashan, Delhi, 2009, 42-60.

21. Zalewski R. I.; Géribaldi, S. J. Chem. Soc., Perkin Trans. 1988, 2, 113-115.

22. Garcia, B.; Casado, R. M.; Castillo, J.; Ibeas, S.; Domingo, I.; Leal, J. M. J. Phys. Org. Chem., 1993, 6, 101-106.

23. Dewar M. J. S.; Dieter, K. M. J. Am. Chem. Soc. 1986, 108, 8075-8086.

24. Steawart, J. J. P. J. Comput. Chem. 1989, 10, 209-216.

25. Ienascu, I. M. C.; Lupea, A. X.; Popescu, I. M.; Padure M. A.; Zamfir, A. D. J. Serb. Chem. Soc. 2009, 74, 847-855.

26. Rajput A. P.; Rajput, S. S. Int. J Pharm. Tech. Research, 2009, 1(4), 1605-1611.

27. Jankulovska, M.; Čolančeska-Rağenoviќ, K.; Dimova, V.; Spirevska I.; Makreski P. Org. Chem., An Ind. J. 2012, 8, 326-334.

28. Jankulovska, M.; Spirevska I.; Ragenoviќ, K. Č. Bull. Chem. Technol. Macedonia, 2006, 25, 29-37.

29. Davis C. T.; Geissman, T. A. J. Am. Chem. Soc. 1954, 76, 3507-3511.

30. E. J. King, Acid-Base Equilibria, Pergamon Press, Oxford, 1965, 1.

31. Dewar, M. J. S.; Zoebisch, E. G.; Healy E. F.; Stewart, J. J. P. J. Am. Chem. Soc. 1985, 107, 39023909.

32. Kireev, V. A. Methods of Practical Calculations in Thermodynamics of Chemical Reactions, Khimiya, Moscow, 1975, 1.

33. Kristallovich, E. L.; Eshimbetov, A. G.; Chuvylkin, V. D.; Belenkii L. I.; Shakhidoyatov, Kh. M. Chem. Nat. Compd. 2003, 39(5), 495-500.

34. Echevarria, A.; Nascimento, M.; Gerônimo, V.; Miller J.; Giesbrecht, A. J. Braz. Chem. Soc. 1999, 10(1), 60-64.

35. Amrallah, A. H.; Abdalla N. A.; Haty, E. El. J. Chin. Chem. Soc. 2006, 53, 697-706.

36. Jankulovska M. S.; Spirevska, I.; Maced. J. Chem. Chem. Eng. 2014, 33(1), 85-96.

37. Perisić-Janjić, N. U.; Lazarević, M.; Janjić, J.; Klisareva, Lj.; U. Scientist Phyl. Sciences. 1995, 7, 6468.

38. Gaubeur, I.; Vincenza, M. R.; Iha, K.; Vázquez, M. E. S. I.; Eclética química. 2000, 25, 63-76. 